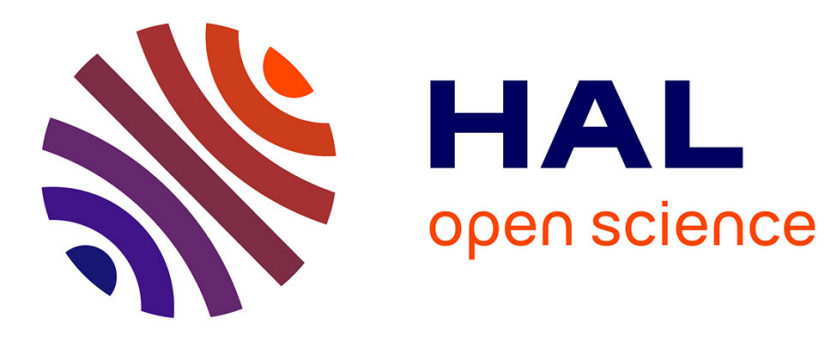

\title{
Mitochondrial function, fatty acid metabolism, and immune system are relevant features of pig adipose tissue development
}

\author{
Annie Vincent, Isabelle Louveau, Florence Gondret, Bénédicte Lebret, Marie \\ Damon
}

\section{To cite this version:}

Annie Vincent, Isabelle Louveau, Florence Gondret, Bénédicte Lebret, Marie Damon. Mitochondrial function, fatty acid metabolism, and immune system are relevant features of pig adipose tissue development. Physiological Genomics, 2012, 44 (22), pp.1116-1124. 10.1152/physiolgenomics.00098.2012 . hal-01210331

\section{HAL Id: hal-01210331 \\ https://hal.science/hal-01210331}

Submitted on 29 May 2020

HAL is a multi-disciplinary open access archive for the deposit and dissemination of scientific research documents, whether they are published or not. The documents may come from teaching and research institutions in France or abroad, or from public or private research centers.
L'archive ouverte pluridisciplinaire HAL, est destinée au dépôt et à la diffusion de documents scientifiques de niveau recherche, publiés ou non, émanant des établissements d'enseignement et de recherche français ou étrangers, des laboratoires publics ou privés.

\section{다(1)(2)}

Distributed under a Creative Commons Attribution - ShareAlikel 4.0 International 


\section{Mitochondrial function, fatty acid metabolism, and}

immune system are relevant features of pig adipose tissue development

Annie Vincent, Isabelle Louveau, Florence Gondret, Bénédicte Lebret and Marie Damon Physiol. Genomics 44:1116-1124, 2012. First published 25 September 2012;

doi: $10.1152 /$ physiolgenomics.00098.2012

You might find this additional info useful...

Supplementary material for this article can be found at:

http://physiolgenomics.physiology.org/http://physiolgenomics.physiology.org/content/suppl/2012/1

0/03/physiolgenomics.00098.2012.DC1.html

This article cites 52 articles, 12 of which you can access for free at:

http://physiolgenomics.physiology.org/content/44/22/1116.full\#ref-list-1

Updated information and services including high resolution figures, can be found at: http://physiolgenomics.physiology.org/content/44/22/1116.full

Additional material and information about Physiological Genomics can be found at: http://www.the-aps.org/publications/physiolgenomics

This information is current as of December 12, 2012. 


\title{
Mitochondrial function, fatty acid metabolism, and immune system are relevant features of pig adipose tissue development
}

\author{
Annie Vincent, ${ }^{1,2}$ Isabelle Louveau, ${ }^{1,2}$ Florence Gondret, ${ }^{1,2}$ Bénédicte Lebret, ${ }^{1,2}$ and Marie Damon ${ }^{1,2}$ \\ ${ }^{1}$ INRA, Unité Mixte de Recherche 1348 Pegase, Saint-Gilles, France; and ${ }^{2}$ Agrocampus Ouest, Unité Mixte de Recherche \\ 1348 Pegase, Rennes, France
}

Submitted 12 July 2012; accepted in final form 21 September 2012

Vincent A, Louveau I, Gondret F, Lebret B, Damon M. Mitochondrial function, fatty acid metabolism, and immune system are relevant features of pig adipose tissue development. Physiol Genomics 44: 1116-1124, 2012. First published September 25, 2012; doi:10.1152/physiolgenomics.00098.2012.-The molecular mechanisms underlying the genetic control of fat development in humans and livestock species still require characterization. To gain insights on gene expression patterns associated with genetic propensity for adiposity, we compared subcutaneous adipose tissue (SCAT) transcriptomics profiles from two contrasted pig breeds for body fatness. Samples were obtained from Large White (LW; lean phenotype) and Basque pigs (B; low growth and high fat content) at $35 \mathrm{~kg}$ ( $n=5$ per breed) or $145 \mathrm{~kg}$ body weight ( $n=10$ per breed). Using a custom adipose tissue microarray, we found 271 genes to be differentially expressed between the two breeds at both stages, out of which 123 were highly expressed in LW pigs and 148 genes were highly expressed in B pigs. Functional enrichment analysis based on gene ontology $(\mathrm{GO})$ terms highlighted gene groups corresponding to the mitochondrial energy metabolism in LW pigs, whereas immune response was found significantly enriched in B pigs. Genes associated with lipid metabolism, such as ELOVL6, a gene involved in fatty acid elongation, had a lower expression in B compared with LW pigs. Furthermore, despite enlarged adipocyte diameters and higher plasma leptin concentration, B pigs displayed reduced lipogenic enzyme activities compared with LW pigs at $145 \mathrm{~kg}$. Altogether, our results suggest that the development of adiposity was associated with a progressive worsening of the metabolic status, leading to a low-grade inflammatory state, and may thus be of significant interest for both livestock production and human health.

adipokine; genotype; inflammation; lipid metabolism; microarray.

EVIDENCE HAS NOW ACCUMULATED to indicate that white adipose tissue plays a major role in the regulation of body fat and energy metabolism. It is now well established that this tissue is not only a site of energy storage but is also an active metabolic and endocrine organ that secretes a number of bioactive peptides or proteins collectively named adipokines and exhibiting numerous functional roles $(11,37)$. In humans, the increase in the prevalence of obesity, now considered as epidemic (OECD obesity update 2012; http://www.oecd.org/dataoecd/1/61/49716427. pdf), highlights the need to prevent and/or treat adipose tissue disturbance that is associated with increased risks of developing metabolic disorders. In the meat industry, body fat content and distribution in growing animals are of special interest for production efficiency and meat quality (27). Taken together, these observations indicate that a better control of fat mass development is of upmost importance for both humans and animals and empha-

Address for reprint requests and other correspondence: I. Louveau, INRA, UMR1348 Pegase, Domaine de la Prise, 35590 Saint-Gilles, France (e-mail: isabelle.louveau@rennes.inra.fr). size the need to elucidate the molecular mechanisms underlying adipose tissue development.

The pig has been recognized for a long time as a suitable animal model for several human disorders $(30,42)$ because of its similar metabolic features, cardiovascular systems, and organ sizes. Therefore, investigation of pig adipose tissue may be very helpful to understand the generic biological processes underlying the development of adiposity. Ascertaining the transcriptome expression profiles variations between breeds exhibiting great differences in adiposity should improve our knowledge of these processes. There is only limited information on the association between transcriptomics profiles and genetic propensity for fat accumulation in this species $(29,36$, 38 ), but all these studies indicate that transcriptional regulation may play a major role in adipose tissue accretion.

In this current study, gene expression profiles of adipose tissue from two genetically distant pig breeds with a contrasted adiposity $(1,26)$ were compared. For this purpose, we developed a custom porcine microarray to get a better understanding of the regulation of adipogenesis and lipid metabolism. To further improve our knowledge on the biological mechanisms associated with fat deposition, we also determined lipogenic capacities of adipose tissue and plasma metabolic indicators in the two breeds.

\section{MATERIALS AND METHODS}

Animals and sample collection. The care and use of pigs were performed in compliance with the European Union legislation (directive 86/609/CEE) and the French legislation (Décret n²001-464 29/05/01; http://ethique.ipbs.fr/sdv/charteexpeanimale.pdf; agreement for animal housing number C-35-275-32). Moreover, the technical and scientific staff obtained an individual agreement from the French Veterinary Services to experiment on living animals. All pigs used in this study were males, surgically castrated at 7 days of age, and weaned at around 4 wk of age. Piglets from the Large White (LW) breed, the most predominant European pig breed used for its high lean growth rate and low fat content, and from the Basque (B) breed, an indigenous French breed with high body fat content and high meat quality, were obtained from selective operators (INRA GEPA, SaintPierre-d'Amilly, France for LW pigs and Anhaux and Lantabat, France, for B pigs). Animals of both breeds entered our experimental facilities (Saint Gilles, France) at 7-8 wk of age and were reared in a conventional housing system (slatted floor, $1.0 \mathrm{~m}^{2} / \mathrm{pig}$ ). They were fed the same standard diets based on cereals according to the following scale: $2.5 \mathrm{~kg} /$ day/pig between 35 and $110 \mathrm{~kg}$, and $3.0 \mathrm{~kg} / \mathrm{day} / \mathrm{pig}$ between 110 and $145 \mathrm{~kg}$.

All pigs were anesthetized by electrical stunning and killed by jugular exsanguination at the average live weight of $35 \mathrm{~kg}(91 \pm 1$ days of age and $121 \pm 3$ days of age for LW and B pigs, respectively; $n=5$ per breed) or $145 \mathrm{~kg}$ ( $229 \pm 19$ days of age and $319 \pm 20$ days of age for LW and B pigs, respectively; $n=10$ per breed). This latter weight was selected because it corresponds to the average slaughter 
weight of B pigs. Immediately after death, blood samples were collected on EDTA and obtained plasma was stored at $-20^{\circ} \mathrm{C}$ until analyses. Backfat thickness was measured with a ruler between the third and the fourth vertebra from the last rib on the carcass. Dorsal subcutaneous adipose tissue (SCAT) samples comprising all fat layers were then taken, cut into small pieces, and frozen in liquid nitrogen. Additional samples were placed on flat sticks and frozen in liquid nitrogen for adipocyte diameter measurements. SCAT samples were stored at $-75^{\circ} \mathrm{C}$ until analyses.

Adipose tissue cellularity. Histological methods were used to determine adipocyte mean diameters. Briefly, frozen adipose tissue was sectioned at $10 \mu \mathrm{m}$ thicknesses with a cryostat at $-30^{\circ} \mathrm{C}$, mounted on slides, and stained with oil red $\mathrm{O}$ solution to reveal lipids into cells, as previously described (13). Images of adipocytes were obtained at a $\times 10$ magnification with a digital camera system. Two slides were prepared per adipose tissue sample, and five images from one slide with the best membrane integrity were retained for cellularity analysis. Adipocyte cross-sectional area of each cell in the image was measured with a digitizing table and a computer image analysis (Visilog 6.0 imaging software; Noesis, Courtaboeuf, France). Results corresponding to the mean of determinations in each adipose tissue sample were expressed as diameter $(\mu \mathrm{m})$, considering adipocytes as spherical cells.

Enzyme assays. Frozen adipose tissue samples (500 mg) were homogenized in $1.5 \mathrm{ml}$ of ice-cold $0.25 \mathrm{M}$ sucrose solution containing $1 \mathrm{mM}$ EDTA and $1 \mathrm{mM}$ DTT. The mixtures were then centrifuged at $100,000 \mathrm{~g}$ for $1 \mathrm{~h}$ at $4^{\circ} \mathrm{C}$. The cytosolic fractions (below the fat cakes) were collected and stored at $-75^{\circ} \mathrm{C}$ until use. Specific activities of fatty acid synthase (FAS; EC: 2.3 .1 .85 ) as the key lipogenic enzyme, and of malic enzyme (ME, EC: 1.1.1.40) as the main supplier of NADPH in the pig were assayed spectrophotometrically at $340 \mathrm{~nm}$ absorbance (2). Substrate quantities $(15-200 \mu \mathrm{l})$ were optimized to ensure the linearity of reactions. Protein content of the cytosolic fractions was determined by Bradford reagent with bovine serum albumin as a standard reference (5). Enzyme activities were then expressed as nanomoles of NADPH per min and per mg of cytosolic proteins. Activities were also expressed per gram of fresh tissue (12).

Plasma parameters. For each parameter, all samples were analyzed in a single batch. Glucose, triglycerides, and nonesterified fatty acids (NEFA) were measured in plasma using a clinical chemistry analyzer Konelab 20i (Thermo Fischer Scientific, Cergy-Pontoise, France). Glucose and triglyceride kits were obtained from BioMérieux (Marcy l'Etoile, France), and the NEFA kit was purchased from Randox (Maugui, France). Intra-assay coefficients of variation (CV) for Konelab measurements were $<5 \%$. Plasma insulin concentrations were measured using a radioimmunoassay (RIA) kit (INSULIN-CT; CisBio Bioassays, Codolet, France). The intra-assay CV was $<5 \%$ at $70 \mu \mathrm{UI} / \mathrm{ml}$. Plasma leptin concentrations were quantified using the multispecies RIA kit (Millipore, St Charles, MO). Intra-assay CV was $<6 \%$. Plasma interleukin-6 (IL6) concentrations were measured with a sandwich enzyme immunoassay technique using a polyclonal antibody specific for porcine IL6 (R\&D Systems, Oxford, UK). The sensitivity of the assay was $2 \mathrm{pg} / \mathrm{ml}$ and the intra-assay CV was $5.1 \%$ at $54 \mathrm{pg} / \mathrm{ml}$.

Total RNA extraction. Samples of frozen adipose tissue (100-300 mg each) were homogenized in TRIzol reagent (Invitrogen, CergyPontoise, France) using a TissueLyser (Qiagen, Courtaboeuf, Paris) and treated according to the manufacturer's instructions for RNA extraction. Afterwards, RNA was purified using a silica-membrane technology (Nucleospin RNA II kit; Macherey Nagel, Hoerdt, France) and quantified using a NanoDrop ND-1000 spectrophotometer (Thermo Scientific, Illkirch, France). The integrity of total RNA was assessed using the Agilent RNA 6000 Nano kit with an Agilent 2100 Bioanalyzer (Agilent Technologies, Massy, France). For later analyses, RNA with RNA Integrity Number $>7$ and A260/280 ratio $>1.8$ were considered.
Agilent $15 \mathrm{~K}$ custom porcine microarray. A custom microarray with 15,017 60-mer oligonucleotides was designed to investigate porcine adipose tissue transcriptome. Briefly, we used 33,000 consensus contig sequences from SIGENAE pig transcript assembly (SIGENAE v8, http://www.sigenae.org) selected from 12 skeletal muscle and one adipose tissue libraries in the PEDE database (Pig EST Data Explorer; http://pede.dna.affrc.go.jp/). These contig sequences were submitted to eARRAY online software v4.5 (Agilent Technologies, http://earray. chem.agilent.com/earray) to design one to two 60 -mer probe(s) per contig sequence (average of 1.33 probes per contig). Analysis of test SCAT RNA samples using all designed probes allowed the selection of 6,845 informative probes. Then, microarray hybridization using SCAT RNA and either NRSP8-Qiagen array (52) or AGENAE 9K microarray (4) allowed, respectively, the selection of 7,834 and 321 additional probes. Lastly, 17 additional probes were selected from the literature. Microarrays were manufactured by in situ synthesis on glass slides using an Agilent 15K (8-plex) microarray format (Agilent Technologies). This repertoire has been deposited in the National Center for Biotechnology Information (NCBI) Gene Express Omnibus (GEO) website (http://www.ncbi.nlm.nih.gov/geo/). The accession number of this new platform is GPL14908.

Transcripts targeted by each of the 60 -mer probes were identified on the basis of probe and contig sequence homology searches using transcripts of pigs (NCBI Sus Scrofa RefSeq http://www.ncbi.nlm. nih.gov/RefSeq/; UniProt, http://www.uniprot.org/) or related species (Homo sapiens, Bos taurus, and Mus musculus). Annotation was based on similarity and quality criteria: at least 18 consecutive base pairs within 60 -mer probe sequence and $85 \%$ of homology (6). The WEB-based GEne SeT AnaLysis Toolkit (http://bioinfo.vanderbilt.edu/webgestalt/) was then used for the categorization of Gene Ontology (GO) terms for biological process (BP).

Labeling of mRNA and microarray hybridization. Each sample was individually labeled with $\mathrm{Cy} 3$ dye. In addition, a reference pool composed of an equal amount of total RNA isolated from all 30 samples was labeled with Cy5 dye to normalize gene expression between samples. For each sample, total RNA (350 ng) was labeled using the Quick-Amp Labeling kit (Agilent Technologies) following the manufacturer's instructions. Briefly, fluorescent complementary RNA (cRNA) was generated by a two-step procedure using T7 RNA polymerase, which simultaneously amplified target and incorporated cyanine-labeled CTP. Samples were then purified with an RNeasy mini elute kit (Qiagen, Hilden, Germany). Microarray hybridizations were carried out at $65^{\circ} \mathrm{C}$ for $17 \mathrm{~h}$ in Agilent's SureHyb hybridization chambers containing $300 \mathrm{ng}$ of Cy3-labeled cRNA sample and $300 \mathrm{ng}$ of Cy5-labeled reference pool per hybridization, using Agilent's Gene Expression Hybridization kit. After being washed, microarrays were scanned at $5 \mu \mathrm{m} /$ pixel resolution using the Agilent DNA Microarray Scanner G2505B, and images were analyzed with Agilent Feature Extraction Software (version 10.5.1.1, protocol GE2_105_Dec08). Microarray data have been approved, and the GEO Series Entry (GSE34161) provides access to all data.

Microarray data analysis. All analyses were performed using the $\mathrm{R}$ software version 2.10.0 (R Development Core Team, 2008). Raw spots intensities were first submitted to quality filtration based on four criteria: intensity, uniformity, saturation, and outlier detection. Intensities of filtered spots were transformed into $\log 2(\mathrm{Cy} 3 / \mathrm{Cy} 5)$, and data were normalized within chips by subtraction of the sample median value across all probes from all raw values and between chips using the "Rquantile" method of the Limma R package (41) to obtain experimentally consolidated gene expression values. The Rquantile method was used since the red channel was a common reference throughout the experiment. To focus on breed effect, we analyzed the two sets of normalized data (35 and $145 \mathrm{~kg}$ ) separately. Data were submitted to an analysis of variance using the fixed effects of breed (LW or B), slide (4 different slides), and their interaction (breed $\times$ slide). Data were then submitted to Benjamini and Hochberg $(\mathrm{BH})$ multiple testing correction procedure (3) with an adjusted $P$ value cutoff of 0.1 . 
Functional analysis. To decipher the genetic basis of adipose tissue development, we chose differentially expressed genes at both $35 \mathrm{~kg}$ and $145 \mathrm{~kg}$ growth stages for further analysis. These genes were arranged into two lists: one with overexpressed genes in B pigs and one group with overexpressed genes in LW pigs. To get these lists more structured and informative, an enrichment analysis for specific GO terms for BP and Kyoto Encyclopedia Genes and Genomes (KEGG) pathways, was carried out using the Database for Annotation, Visualization and Integrated Discovery (DAVID) bioinformatics resources (http://david.abcc.ncifcrf.gov/home.jsp; 10, 20). In DAVID analysis, the GO terms_FAT were selected to filter the broadest terms without overshadowing the more specific ones. The two lists of genes were uploaded using ENTREZ gene ID (http://www.ncbi.nlm.nih. gov/gene). The $P$ values for enrichment were computed by the $\mathrm{BH}$ multiple testing correction technique, using our custom microarray (i.e., 9,532 human ENTREZ gene ID) as background.

Reverse transcription and quantitative real-time PCR. The expression of nine genes found to be differentially expressed between LW and $\mathrm{B}$ pigs by the microarray study was further analyzed. Expression of four genes overexpressed in the B pigs, i.e., FBJ murine osteosarcoma viral oncogene homolog (FOS); interleukin 6 (IL6); cathepsin S (CTSS); colony stimulating factor 1 receptor (CSF1R); and of five genes overexpressed in the LW pigs: elongation of very long chain fatty acids elongase 6 (ELOVL6); fatty acid binding protein 3, muscle and heart (FABP3); ATP synthase, $\mathrm{H}^{+}$transporting, mitochondrial $\mathrm{F} 1$ complex, beta polypeptide (ATP5B); ubiquinol-cytochrome c reductase core protein 1 (UQCRC1); and insulin-like growth factor 2 (IGF2) were quantified by quantitative real-time PCR (qPCR). The expression of the tumor necrosis factor (TNF)- $\alpha$ gene, which was not included in the custom microarray, was also determined. cDNA was synthesized from $1 \mu \mathrm{g}$ of total RNA using a high-capacity cDNA reverse transcription kit (Applied Biosystems, Foster City, CA). Primers (Table 1) were designed from porcine sequences using Primer
Express software 3.0 (Applied Biosystems). For each primer pair, the amplification efficiency of qPCR reaction was determined by calibration curves generated with six decreasing concentrations of cDNA pool samples (12.5-12.5E $\mathrm{E}^{-03} \mathrm{ng}$ RNA). Amplification reaction was performed in triplicate in $12.5 \mu \mathrm{l}$ with $2.5 \mathrm{ng}$ of reverse-transcribed RNA and both forward and reverse primers (200 nM each) in $1 \times$ PCR buffer (Fast SYBR Green Master Mix, Applied Biosystems), using a StepOnePlus Real Time PCR system (Applied Biosystems). Thermal cycling conditions were as follows: $50^{\circ} \mathrm{C}$ for $2 \mathrm{~min}, 95^{\circ} \mathrm{C}$ for $20 \mathrm{~s}$, followed by 40 cycles of denaturation at $95^{\circ} \mathrm{C}$ for $3 \mathrm{~s}$, and annealing at $60^{\circ} \mathrm{C}$ for $30 \mathrm{~s}$. Specificity of the amplification products was checked by dissociation curves analysis. Three genes were retained as the most stable reference genes for normalization using geNorm algorithm (45): hypoxanthine phosphoribosyltransferase 1 (HPRT1), beta 2 microglobulin (B2M), and TATA box binding protein (TBP). For each sample, a normalization factor (NF) was calculated using geNorm algorithm and used for subsequent normalization. For each gene, the normalized expression level $\mathrm{N}$ was calculated according to the following

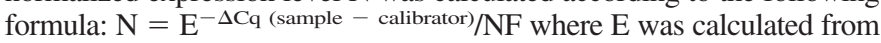
the slope of calibration curve, $\mathrm{Cq}$ was the quantification cycle, and calibrator was a pool of all the SCAT samples.

Statistical analysis for nonmicroarray data. Adipose tissue cellularity, plasma parameter levels, and qPCR data were submitted to an analysis of variance considering the fixed effect of breed in the model ( $\mathrm{R}$ software version 2.10.0, R Development Core Team, 2008). Differences were considered significant at $P \leq 0.05$. $P$ value between 0.05 and 0.10 was discussed as a trend.

\section{RESULTS}

Adipose tissue and plasma features at $145 \mathrm{~kg}$ body weight. Mean backfat thickness was 2.5 -fold higher $(P<0.001)$, and mean diameters of subcutaneous adipocytes were also greater

Table 1. Primer sequences used for analysis of gene expression by $q P C R$

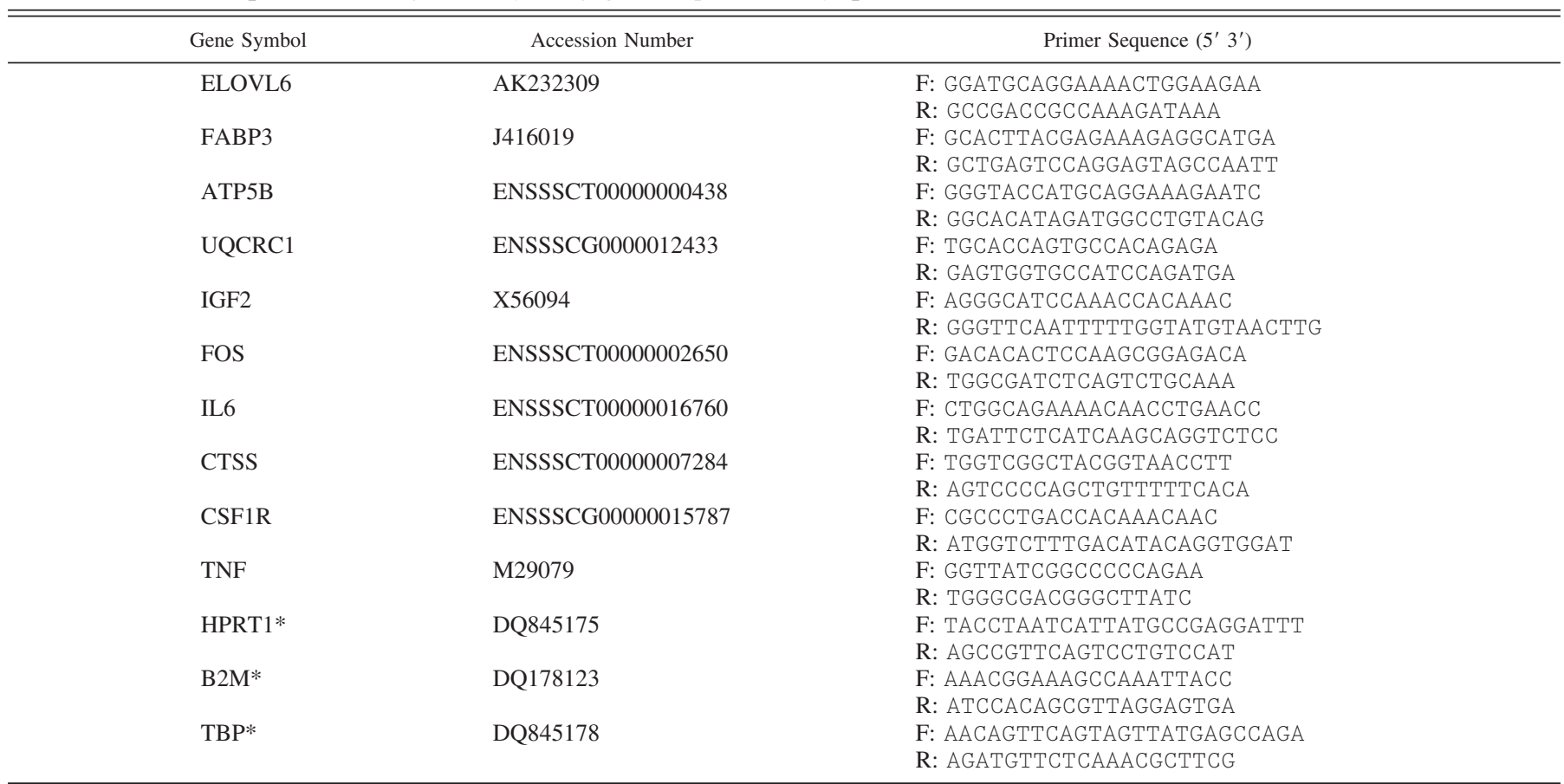

Accession numbers are from the National Center for Biotechnology Information (NCBI) and Ensembl project databases for pig sequences. F and R indicate forward and reverse primers, respectively. *Gene used as reference for normalization. ELOVL6, elongation of very long chain fatty acid protein 6; FABP3, fatty acid binding protein 3; ATP5B, ATP synthase subunit beta, mitochondrial; UQCRC1, ubiquinol-cytochrome c reductase core protein 1; IGF2, insulin-like growth factor 2; FOS, proto-oncogene c-fos; IL6, interleukin 6; CTSS, cathepsin S; CSF1R, colony stimulating factor 1 receptor; TNF, tumor necrosis factor- $\alpha$; HPRT1, hypoxanthine phosphoribosyltransferase 1; B2M, beta 2 microglobulin; TBP, TATA box binding protein. 
Table 2. Subcutaneous adipose tissue features, plasma parameters, and expression of lipid metabolism genes in LW and $B$ pigs at $145 \mathrm{~kg}$

\begin{tabular}{|c|c|c|c|}
\hline & LW & B & $P$ Value \\
\hline \multicolumn{4}{|c|}{ Subcutaneous adipose tissue features } \\
\hline Backfat thickness, mm & $18.7 \pm 1.3$ & $45.4 \pm 2.4$ & $<0.001$ \\
\hline \multicolumn{3}{|l|}{ Malic enzyme } & $<0.001$ \\
\hline $\mathrm{nmol} / \mathrm{min} / \mathrm{mg}$ prot & $1124 \pm 89$ & $667 \pm 34$ & $<0.001$ \\
\hline $\mathrm{nmol} / \mathrm{min} / \mathrm{g}$ tissue & $2944 \pm 333$ & $940 \pm 58$ & $<0.001$ \\
\hline \multicolumn{4}{|l|}{ Fatty acid synthase } \\
\hline $\mathrm{nmol} / \mathrm{min} / \mathrm{mg}$ prot & $31 \pm 5$ & $28 \pm 4$ & 0.609 \\
\hline $\mathrm{nmol} / \mathrm{min} / \mathrm{g}$ tissue & $90.4 \pm 17$ & $44.4 \pm 8$ & 0.02 \\
\hline \multicolumn{4}{|c|}{ Plasma parameters } \\
\hline Triglycerides, mg/l & $592 \pm 51$ & $569 \pm 23$ & 0.680 \\
\hline NEFA, $\mu \mathrm{mol} / 1$ & $356 \pm 58$ & $488 \pm 46$ & 0.093 \\
\hline Glucose, $\mu \mathrm{mol} / \mathrm{ml}$ & $5.67 \pm 0.34$ & $5.31 \pm 0.24$ & 0.394 \\
\hline Insulin, $\mu \mathrm{UI} / \mathrm{ml}$ & $22.5 \pm 2.2$ & $30.4 \pm 4$ & 0.102 \\
\hline Leptin, ng/ml & $2.7 \pm 0.2$ & $3.6 \pm 0.4$ & 0.035 \\
\hline \multicolumn{4}{|c|}{ Microarray expression levels of genes involved in fatty acid metabolism } \\
\hline ACSL1 & $1.96 \pm 0.22$ & $0.86 \pm 0.09$ & $<0.001$ \\
\hline FABP4 & $0.84 \pm 0.05$ & $1.09 \pm 0.04$ & 0.003 \\
\hline APOE & $1.17 \pm 0.09$ & $1.59 \pm 0.05$ & $<0.001$ \\
\hline \multicolumn{4}{|c|}{$\begin{array}{l}\text { Data are presented as means } \pm \text { SE }(n=10 / \text { breed). } P \text { value, level of } \\
\text { significance of the difference between breeds. LW, Large White; B, Basque; } \\
\text { NEFA, nonesterified fatty acids. Levels of mRNA (microarray data) for } \\
\text { acyl-CoA synthetase long chain family, member } 1 \text { (ACSL1), fatty acid binding } \\
\text { protein } 4 \text { (FABP4), and apolipoprotein E (APOE) were normalized to the } \\
\text { median value across all probes. }\end{array}$} \\
\hline
\end{tabular}

$(P<0.001)$ in B than in LW pigs (Table 2$)$. Specific activity of malic enzyme (ME) was lower $(P<0.001)$ in B than in LW pigs, whereas specific activity of FAS was similar in the two breeds. When expressed per weight of SCAT, the two lipogenic enzyme activities were reduced $(P<0.05)$ in B compared with LW pigs. To provide additional information on lipid metabolism in these breeds, other blood parameters were investigated (Table 2). Circulating leptin concentrations were higher $(P<0.05)$ in B than in LW pigs. Plasma concentrations of insulin and NEFA tended to be higher $(P \leq 0.1)$ in B than in LW pigs, whereas plasma concentrations of glucose and triglycerides did not differ between breeds.

Custom porcine microarray. With the $15 \mathrm{~K}$ porcine microarray developed in this study, we validated at least one annotation for 12,120 probes (80\%), corresponding to 9,532 human Entrez gene ID. In the web-based GEne SeT AnaLysis Toolkit for the categorization of GO BP terms, the GO-slim (i.e., representing high-level $\mathrm{GO}$ ) terms was used to focus on the most important processes. As shown in Fig. 1, the 9,532 genes of the microarray encoded proteins involved in 13 biological processes. The metabolic process category represented almost $50 \%$ of the genes of the microarray, whereas the GO category including genes related to growth accounted for $<3 \%$ of the genes. About $25 \%$ of the genes were not related to any BP.

Transcriptomes of adipose tissue in B and LW pigs at $35 \mathrm{~kg}$ and $145 \mathrm{~kg}$. Among the 8,369 probes kept for statistical analysis after filtration for spot quality, $1,108(13 \%)$ probes were differentially expressed (adjusted $P$ value $<0.1$ ) between $\mathrm{B}$ and $\mathrm{LW}$ pigs at $35 \mathrm{~kg}$ and $1,474(18 \%)$ probes were differentially expressed at $145 \mathrm{~kg}$ (Fig. 2). For example, at 145 $\mathrm{kg}$, the microarray expression level of acyl-CoA synthetase

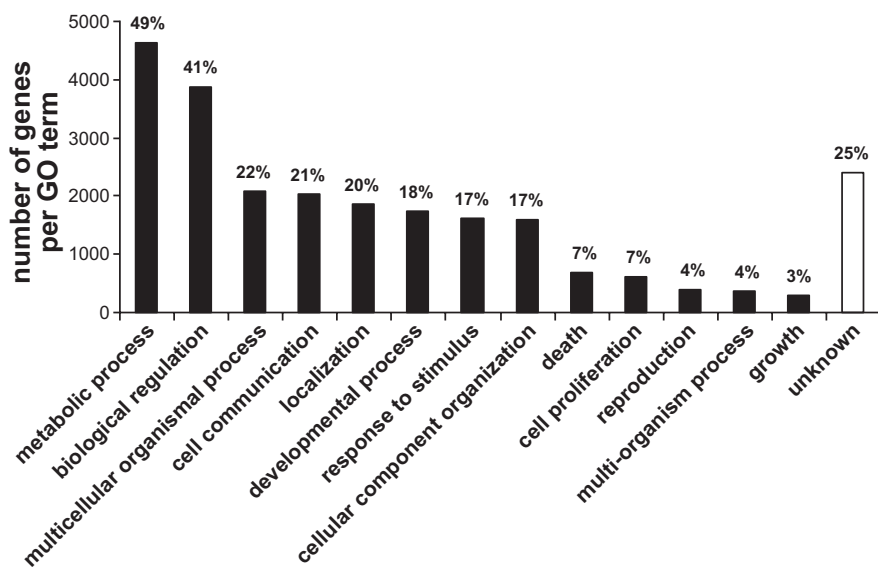

Fig. 1. Microarray biological process (GO Slim) classification. Each biological process category is represented by a bar. The height of the bar represents the number of genes observed in the category. The percentage of genes per category is indicated upon the bar text.

(ASCL1) was lower in B than in LW pigs, whereas expressions of fatty acid binding protein 4 (FABP4) and apolipoprotein E (APOE) were greater in B pigs than in LW pigs (Table 2). Expression levels of these genes did not differ between the two breeds at $35 \mathrm{~kg}$ body weight.

Out of the breed-differentially expressed probes, 359 had significant different expression at both physiological stages. They were thus considered of high interest to highlight breed specific differences and retained for further analyses. Among these 359 probes representing 271 genes, 152 probes representing 123 genes were overexpressed in LW pigs (Supplemental Table S1), whereas 207 probes representing 148 genes were overexpressed in B pigs (Supplemental Table S2). ${ }^{1}$ Foldchanges (FC; i.e., expression ratio between $\mathrm{B}$ and $\mathrm{LW}$ breeds) varied from 1.1 to 6.5 , with median $\mathrm{FC}$ of 1.3 for genes overexpressed in LW pigs and of 1.5 for genes overexpressed in B pigs (Fig. 3).

Functional analysis of differentially expressed genes between breeds. To identify the main BP terms related to breed specificities, the two lists of genes highly expressed either in LW (i.e., 123) or in B pigs (i.e., 148) were submitted to an enrichment analysis for GO BP using DAVID bioinformatics resources. The KEGG pathway database was used to identify

${ }^{1}$ The online version of this article contains supplemental material.

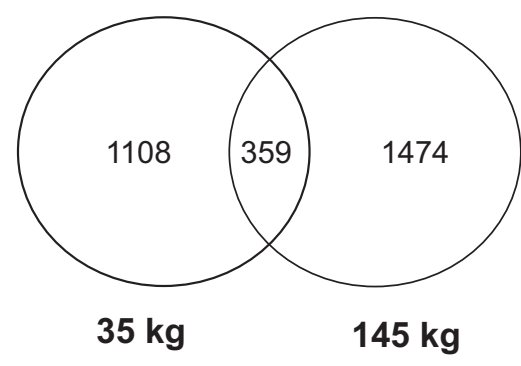

Stages of growth

Fig. 2. Venn diagram of differentially expressed probes between subcutaneous adipose tissue of Large White (LW) and Basque (B) pigs at 35 and $145 \mathrm{~kg}$. 


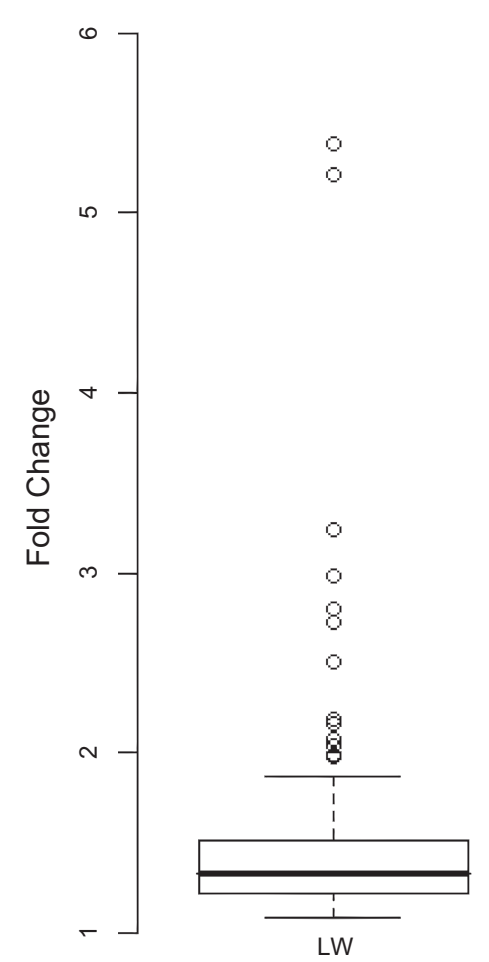

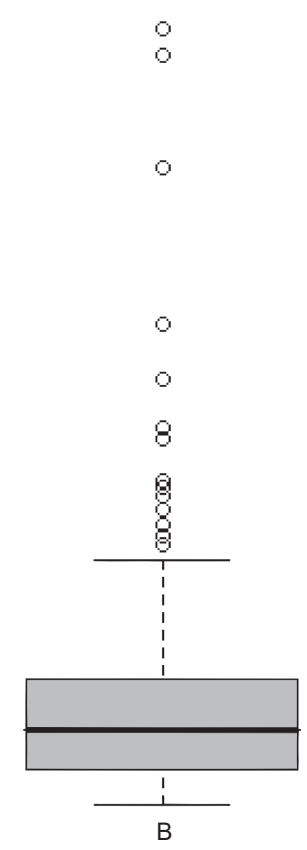

Fig. 3. Range of differential gene expression between LW and B pigs at $145 \mathrm{~kg}$.

additional molecular interaction and reaction networks. In LW pigs, 12 GO BP terms were overrepresented $(P$ value $<$ $8.4 \mathrm{E}^{-03}$ and fold enrichment $>5.9$ ) relative to microarray background (Table 3). Among them, two GO BP terms were associated with translation, whereas all the other terms were related to mitochondrial energy metabolism. Among them, the generation of precursor metabolites and energy was the category including the greatest number of associated genes with 18 genes encoding four mitochondrial electron transfer chain complex subunits. Furthermore, the KEGG oxidative phos- phorylation pathway was also overrepresented in LW pigs. This pathway included 17 genes encoding subunits of the electron transfer chain complexes I, III, IV, and V.

For B pigs, six GO BP terms were overrepresented $(P$ value $<$ $5.4 \mathrm{E}^{-02}$ and fold enrichment $>2.3$ ) relative to microarray background (Table 4). Among these enriched categories, the immune response and intracellular signaling cascade were the most significant. The immune response category included IL6 and various chemokines, such as chemokine (C-X-C motif) ligand 2 (CXCL2), chemokine (C-C motif) ligand 4 (CCL4), and chemokine (C-C motif) ligand 19 (CCL19). A significant enrichment in two terms related to the actin cytoskeleton was also observed in B breed. Finally, response to cytokine stimulus and cell-motion BP were also enriched in B pigs.

qPCR confirmations. Up- or downregulations in B vs. LW pigs of nine genes selected for their role in relevant functional categories, such as mitochondrial electron transport (UQCRC1), immune response (IL6, CTSS, CSF1R, FOS), fatty acid metabolic process (ELOVL6, FABP3, ATP5B), and regulation of transcription (IGF2), was further confirmed by qPCR. In agreement with microarray analyses, target genes related to immune response were overexpressed in B pigs at $145 \mathrm{~kg}(P<0.1)$, whereas those related to mitochondrial and fatty acid metabolisms were downregulated $(P<0.05)$ in B compared with LW pigs (Fig. 4). The expression level of TNF that encodes a multifunctional proinflammatory cytokine tended $(P<0.1)$ to be greater in B pigs than in LW pigs at $145 \mathrm{~kg}$.

\section{DISCUSSION}

The comparison between a lean-type and a fat-type pig breed, both raised under the same nutritional conditions, allowed the identification of the main molecular pathways associated with a genetic propensity for body fat accumulation. Data available in this area of research in humans and rodents are based mainly on investigations in adults. With the pig being recognized as a suitable animal model for several human disorders $(30,42)$, the current findings in growing pigs are thus relevant to enrich our knowledge regarding the dynamic changes in adipose tissue development according to genetic background.

Table 3. Relevant GO BP and KEGG pathways significantly enriched in the subcutaneous adipose tissue of LW pigs

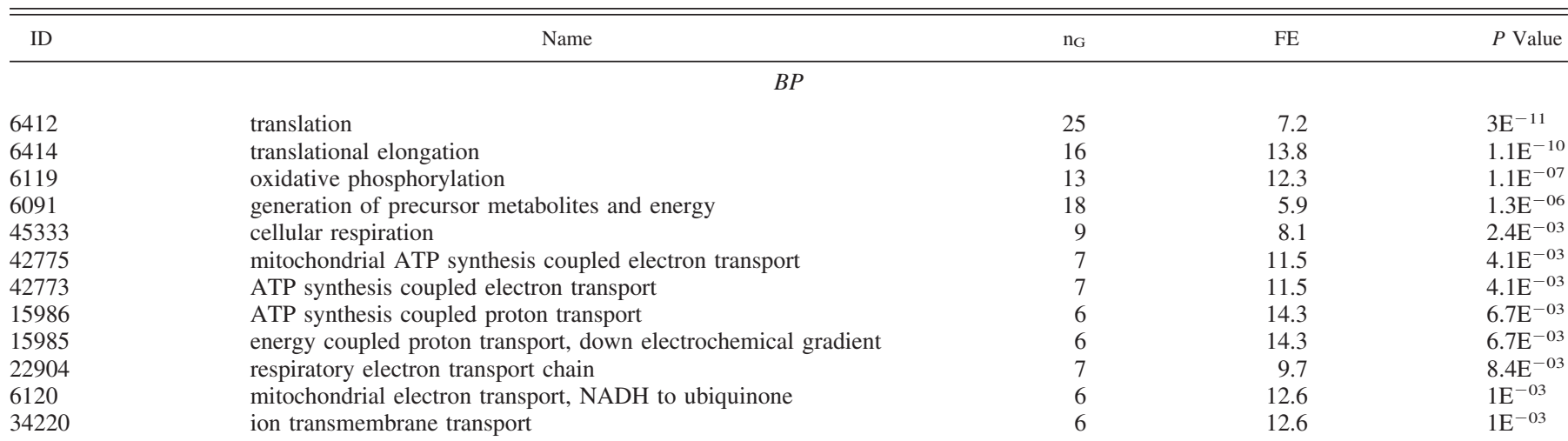

$K E G G$

BP, biological process; ID, Gene Ontology (GO) BP or KEGG pathway identification number; $\mathrm{n}_{\mathrm{G}}$, number of genes in the category; FE, fold enrichment. i.e., $\%$ of differentially expressed genes vs. $\%$ of genes in background population; $P$ value, enrichment $P$ value after multiple testing correction according to Benjamini-Hochberg. 
Table 4. Relevant GO BP significantly enriched in the subcutaneous adipose tissue of B pigs

\begin{tabular}{|c|c|c|c|c|c|}
\hline Category & ID & Ontology Name & $\mathrm{n}_{\mathrm{G}}$ & FE & $P$ value \\
\hline \multirow[t]{6}{*}{$\mathrm{BP}$} & 6955 & immune response & 15 & 3.6 & $2.4 \mathrm{E}^{-02}$ \\
\hline & 7242 & intracellular signaling cascade & 25 & 2.3 & $2.9 \mathrm{E}^{-02}$ \\
\hline & 30029 & actin filament-based process & 11 & 4.7 & $3.1 \mathrm{E}^{-02}$ \\
\hline & 30036 & actin cytoskeleton organization & 11 & 5 & $3.5 \mathrm{E}^{-02}$ \\
\hline & 34097 & response to cytokine stimulus & 7 & 10.4 & $5.3 \mathrm{E}^{-02}$ \\
\hline & 6928 & cell motion & 14 & 3.3 & $5.4 \mathrm{E}^{-02}$ \\
\hline
\end{tabular}

For definition of abbreviations, see Table 3.

Breed-associated differences in body fat phenotype were clearly proved by the contrasted backfat thickness and large variation in adipocyte mean diameters as reported previously (1). Despite these large differences, plasma parameters associated with glucose and lipid metabolism differed only slightly between $\mathrm{B}$ and LW pigs, indicating no signs of metabolic disorders at this growth stage except a trend for higher insulinemia and circulating NEFA in B pigs compared with LW pigs. The highest concentration in plasma leptin in B compared with LW pigs confirms the role of leptin as a relevant marker of adiposity in pigs, as in humans (39).

The porcine custom microarray developed in this study allows the identification of marked differences in transcriptome profile of adipose tissue, with $>1,000$ genes differentially expressed between $\mathrm{B}$ and LW pigs exhibiting similar body weights. These findings reinforce the view that transcriptional regulation in adipose tissue is a key feature in genetically related differences in adiposity, as shown by a recent study on deep high-throughput sequencing of porcine adipose tissue (29). The fact that only $25 \%$ of the differentially expressed genes were commonly modulated at the two stages of growth

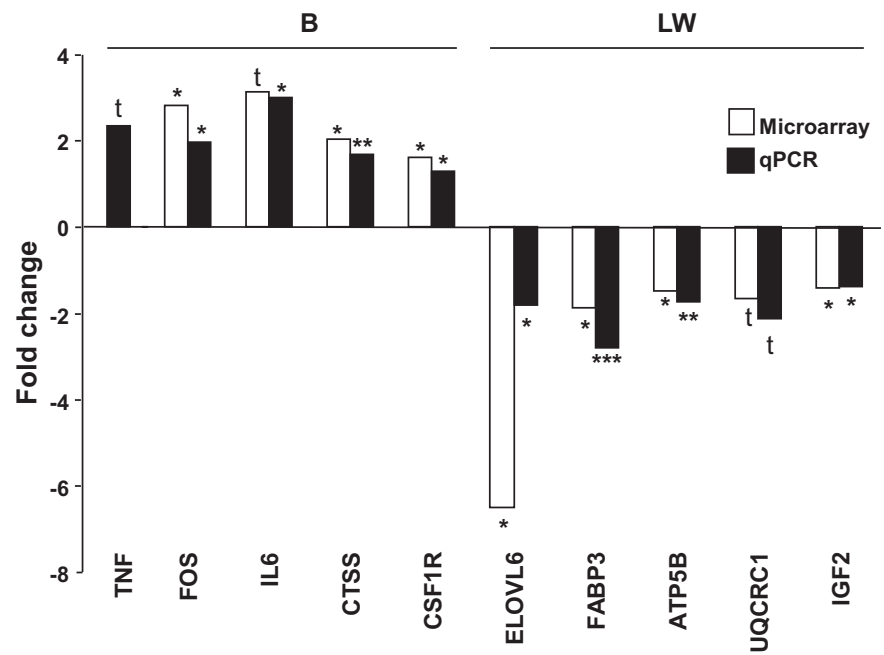

Fig. 4. Differentially expressed genes identified by microarray or qPCR in adipose tissue of LW and B pigs. Data were obtained from pigs sampled at 145 $\mathrm{kg}(n=10 / \mathrm{breed})$ and are expressed as the expression ratio of $\mathrm{B}$ to $\mathrm{LW}$ samples. Ratios $<1$ are expressed as negative numbers (i.e., a ratio of 0.5 is expressed as -2). Significance levels are reported on the plot as BenjaminiHochberg adjusted $P$ value for microarray data, and as ANOVA $P$ value for qPCR data. $* P$ value $<0.05, * * P$ value $<0.01, * * * P$ value $<0.001,{ }^{\text {t }} P$ value $<0.1$. ATP5B, ATP synthase subunit beta, mitochondrial; CSF1R, colony stimulating factor 1 receptor; CTSS, cathepsin S; ELOVL6, elongation of very long chain fatty acid protein 6; FABP3, fatty acid binding protein 3; FOS, Proto-oncogene c-fos; IGF2, insulin-like growth factor 2; IL6, interleukin 6; UQCRC1, ubiquinolcytochrome $\mathrm{c}$ reductase core protein $1 ; \mathrm{TNF}$, tumor necrosis factor- $\alpha$. considered in this study suggests that the temporal expression pattern of many genes may differ between the two breeds. For instance, the expression level of ACSL1, a gene encoding lipogenic long-chain acyl-CoA synthetase 1 enzyme, was more than twofold lower in B than in LW pigs at $145 \mathrm{~kg}$, whereas its expression was similar in $35 \mathrm{~kg}$ pigs of both breeds. Similarly, a greater expression of APOE in adipose tissue of B compared with LW pigs was found at $145 \mathrm{~kg}$ only. This observation supports the idea that fatty acids may play a positive role in enabling a continuous triacylglycerol accretion in adipose tissue along growth in pigs with high body fat content. This gene, encoding an endogenous apolipoprotein to facilitate tissue lipid uptake from circulating lipoproteins (21), has also been reported to correlate positively with cellular lipid content in differentiated mouse adipocytes and human adipose tissue (51). In contrast, high-throughput sequencing of adipose tissue has indicated a greater expression level of APOE in lean pigs than in adult obese pigs (29). Altogether, available data indicate that the role of APOE needs further investigation. Moreover, because the expression level of APOE has been reported to be greater in adults than in young pigs (29), the nature of the breed-regulated genes involved in fatty acid metabolism are likely partly dependent of the growth phase considered. Indeed, when comparing SCAT lipogenic enzyme activities between Meishan and LW pigs during growth, Mourot et al. (34) reported an earlier maximum lipogenic capacity followed by a progressive decrease during growth in Meishan pigs, whereas maximum lipogenic capacity was obtained later and remained higher in LW pigs with advancing age. We can thus hypothesize that adipose tissue, the main site of lipogenesis in the pig, reached a maximum lipogenic capacity much earlier in B pigs than in LW pigs, as found in Meishan pigs (34). This hypothesis is supported by the finding of a lower ME activity in SCAT of $\mathrm{B}$ than LW pigs at $145 \mathrm{~kg}$, whereas activities of NADPHproducing enzymes (ME and glucose-6-phosphate dehydrogenase) were positively associated with adiposity in $35 \mathrm{~kg}$ pigs of the same two breeds (15). Analysis of genes that were commonly affected at the onset and at the end of the growing period highlighted two additional genes involved in fatty acid metabolism, ELOVL6 and FABP3, with low expression in B pigs compared with LW pigs. The decreased expression of ELOVL6, which specifically catalyzes the elongation of longchain fatty acids from $\mathrm{C} 12$ to $\mathrm{C} 18$ agrees with data recently obtained in dogs during the transition from a lean to an obese phenotype (17). Moreover, ELOVL6-deficient mice have been shown to become obese but without developing insulin resistance, when fed a high-fat diet (32). Besides, the lower gene expression of FAPB3 further supports a less active metabolism of long chain fatty acids (14) in B compared with in LW pigs. 
Whatever the growth stage considered, the expression of genes involved in immune-inflammatory response was markedly higher in B than in LW pigs, whereas several genes associated with mitochondrial energy metabolism exhibited a low expression in B compared with LW pigs. In accordance with our results, increased immune response and decreased metabolism have been shown as the main molecular adaptations in subcutaneous and visceral adipose tissue of humans during the development of obesity and metabolic disorders (25). In the pig, $60 \%$ of the genes expressed in isolated adipocytes from SCAT have been reported to be of mitochondrial origin (8). The lower expression of genes associated to mitochondrial energy and electron transport pathway in B than LW pigs is also consistent with previous studies in humans (25, 28) or ob/ob mice (49), showing a decrease in the abundance of numerous gene transcripts encoding mitochondrial proteins in adipose tissue at the onset of obesity. In particular, the downregulation of silent mating type information regulation 2 homolog 3 (SIRT3) in B pigs further suggests a reduced fat oxidation in this fat-type breed compared with the lean-type LW pigs (19), even though this gene is generally considered as poorly expressed in white adipose tissue compared with brown adipose tissue in other species (40). Importantly, studies showing a crucial role of mitochondria in white adipose tissue physiology and metabolism have been based on investigations in humans or rodents exhibiting severe obesity-associated disorders $(9,47)$, whereas experimental fat-type pigs in the current study did not show any evidence of associated-metabolic disorders.

The higher adiposity of B compared with LW pigs was associated with the upregulation in SCAT of genes involved in the immune response as reported in dog adipose tissue during obesity development (17). Genes related to immune response and inflammation were also found overrepresented in adipose tissue of obese humans and rodents $(18,23,25,28,50)$. Because the whole adipose tissue was analyzed in the present study, we cannot ascertain the cell type(s) involved in the observed breed differences. Upregulation of some genes may be related to macrophage infiltration in adipose tissue of $\mathrm{B}$ pigs, as shown in rodent and human adipose tissue (48). We have, however, no definitive evidence for such a macrophage infiltration in adipose tissue. Indeed, only CSF1R, a macrophage-specific gene (35), was found overexpressed in B pigs, whereas expression levels of genes such as CD68, CD14, C163, IRF5, or MSR1, described as macrophagespecific markers (24), were similar in both breeds (data not shown). It is also possible that other cells like preadipocytes can convert into macrophages (7). Moreover, the adipocyte production of proinflammatory cytokines TNF- $\alpha$ and IL6, encoded by two genes that were found upregulated in adipose tissue of B pigs, cannot be totally excluded. Indeed, porcine adipocytes isolated from subcutaneous and perivisceral adipose tissues have been shown to express TNF and IL6 genes during development (13). In this study, we failed to demonstrate any differences in circulating levels of IL- 6 between the two breeds, even though a strong relation between circulating levels and adipose tissue expression of TNF and IL6 has been found in obese humans (31). Actually, excessive fat accumulation, and more generally obesity, is often considered as a chronic state of low-grade inflammation. Although plasma haptoglobin concentrations were similar in our B and LW pigs
(33), expression levels of several genes are consistent with a greater propensity to develop inflammation in the B pigs. Indeed, the major acute phase protein (MAP)/inter-alpha-trypsin inhibitor heavy chain family, member 4 (ITIH4), which had a greater expression level in B than in LW pigs, was upregulated during cytokine-mediated inflammation in porcine hepatocytes (16). Moreover, the cytochrome P450, family 3, subfamily A, polypeptide 4 (CYP3A4), found upregulated in B pigs, could promote adipocyte proliferation and triglyceride accumulation through reactive oxygen species production (46). Finally, B pigs exhibiting lower expression of mitochondrial heat shock protein 10 (HSP10), known to exert anti-inflammatory activity (22), might be more prone to inflammatory process.

The current study also reveals that genes related to cytoskeleton may be important for the genetic propensity to develop fat. There may be an extensive remodeling of extracellular matrix. When adipocytes reach their maximal capacity for triglyceride storage, a proportion of cells may undergo necrotic cell death, which is thought to result in the recruitment of macrophages to clear the necrotic debris and remodel the enlarging adipose tissue (43). CTSS, a cysteine protease belonging to the cathepsin family, may play a significant role in this pathway. Indeed, cathepsins have been shown to be involved in atherogenesis and may interfere in the induction of metabolic disorders (44), by acting as a link between adipose tissue development and arterial alterations in human obesity.

In conclusion, the excessive accumulation of body fat in B pigs was associated with modulations in biochemical characteristics and transcriptional processes within adipose tissue without any clear evidence of metabolic disorders. Gene expression profile suggests that the increase in body fat altered the immune system and strengthened the relationships between adipose tissue, immunity, and metabolism. In terms of dynamics of development, the present results highlight lipogenesis as the first metabolic process affected by fat accretion, accompanied by a decline in the expression of genes linked to mitochondria functions. As a whole, fat accretion in B pigs occurred through fatty acid depots and was progressively associated with a worsening of metabolic status and an inflammatory state that may lead to metabolic disorders in later life. These new findings on the influence of genetic background on fat accretion are of significant interest for both animal breeding and human health.

\section{ACKNOWLEDGMENTS}

The authors thank C. Tréfeu and J. Wyszynska-Koko for skillful assistance; N. Bonhomme, P. Ecolan, and S. Tacher for sample collection; and M. Alix, J. Liger, and J.F. Rouaud for animal slaughtering. They acknowledge all the staff involved in the care and feeding of animals. F. Moreews from the Sigenae team is also acknowledged for annotating the Agilent porcine custom microarray.

\section{GRANTS}

The authors gratefully acknowledge the European Community financial participation under the Sixth Framework Program for Research, Technological Development and Demonstration activities, for the Integrated Project QPORKCHAINS FOOD-CT-2007-036245. The views expressed in this publication are the sole responsibility of the authors and do not necessarily reflect the views of the European Commission. Neither the European Commission nor any person acting on behalf of the Commission is responsible for the use, which might be made of the information. The information in this document is provided as is and no guarantee or warranty is given that the information is fit for any particular purpose. The user thereof uses the information at its sole risk and liability. 


\section{DISCLOSURES}

No conflicts of interest, financial or otherwise, are declared by the author(s).

\section{AUTHOR CONTRIBUTIONS}

Author contributions: A.V. performed experiments; A.V., I.L., and M.D. analyzed data; A.V., I.L., and M.D. interpreted results of experiments; A.V. and M.D. prepared figures; A.V., I.L., and M.D. drafted manuscript; A.V., I.L., F.G., B.L., and M.D. approved final version of manuscript; I.L., F.G., B.L., and M.D. conception and design of research.

\section{REFERENCES}

1. Alfonso L, Mourot J, Insausti K, Mendizabal JA, Arana A. Comparative description of growth, fat deposition, carcass and meat quality characteristics of Basque and Large White pigs. Anim Res 54: 33-42, 2005.

2. Bazin R, Ferre P. Assays of lipogenic enzymes. Methods Mol Bio 155: 121-127, 2001.

3. Benjamini Y, Hochberg Y. Controlling the false discovery rate-A practical and powerful approach to multiple testing. J Roy Stat Soc, Series B 57: 289-300, 1995.

4. Bonnet A, Iannuccelli E, Hugot K, Benne F, Bonaldo MF, Soares MB, Hatey F, Tosser-Klopp G. A pig multi-tissue normalised cDNA library: large-scale sequencing, cluster analysis and $9 \mathrm{~K}$ micro-array resource generation. BMC Genomics 9: 17, 2008.

5. Bradford MM. Rapid and sensitive method for quantitation of microgram quantities of protein utilizing principle of protein-dye binding. Anal Biochem 72: 248-254, 1976.

6. Casel P, Moreews F, Lagarrigue S, Klopp C. sigReannot: an oligo-set re-annotation pipeline based on similarities with the Ensembl transcripts and Unigene clusters. BMC Proc 3, Suppl 4: S3, 2009.

7. Charriere G, Cousin B, Arnaud E, Andre M, Bacou F, Penicaud L, Casteilla L. Preadipocyte conversion to macrophage - Evidence of plasticity. J Biol Chem 278: 9850-9855, 2003.

8. Chen CH, Lin EC, Cheng WTK, Sun HS, Mersmann HJ, Ding ST. Abundantly expressed genes in pig adipose tissue: an expressed sequence tag approach. J Anim Sci 84: 2673-2683, 2006.

9. De Pauw A, Tejerina S, Raes M, Keijer J, Arnould T. Mitochondrial (dys)function in adipocyte (de)differentiation and systemic metabolic alterations. Am J Pathol 175: 927-939, 2009.

10. Dennis G, Sherman BT, Hosack DA, Yang J, Gao W, Lane HC, Lempicki RA. DAVID: Database for annotation, visualization, and integrated discovery. Genome Biol 4: P3, 2003.

11. Galic S, Oakhill JS, Steinberg GR. Adipose tissue as an endocrine organ. Mol Cell Endocrinol 316: 129-139, 2010.

12. Gandemer G, Pascal G, Durand G. Comparative changes in the lipogenic enzyme-activities and in the in vivo fatty-acid synthesis in liver and adipose tissues during the post-weaning growth of male-rats. Comp Biochem Physiol B 82: 581-586, 1985.

13. Gardan D, Gondret F, Louveau I. Lipid metabolism and secretory function of porcine intramuscular adipocytes compared with subcutaneous and perirenal adipocytes. Am J Physiol Endocrinol Metab 291: E372E380, 2006.

14. Glatz JFC, Schaap FG, Binas B, Bonen A, van der Vusse GJ, Luiken J. Cytoplasmic fatty acid-binding protein facilitates fatty acid utilization by skeletal muscle. Acta Physiol Scand 178: 367-371, 2003.

15. Gondret F, Guevel B, Com E, Vincent A, Lebret B. A comparison of subcutaneous adipose tissue proteomes in juvenile piglets with a contrasted adiposity underscored similarities with human obesity. J Proteom 75: 949-961, 2012.

16. Gonzalez-Ramon N, Hoebe K, Alava MA, van Leengoed L, Pineiro M, Carmona S, Iturralde M, Lampreave F, Pineiro A. Pig MAP/ITIH4 and haptoglobin are interleukin-6-dependent acute-phase plasma proteins in porcine primary cultured hepatocytes. Eur J Biochem 267: 1878-1885, 2000

17. Grant RW, Boler BMV, Ridge TK, Graves TK, Swanson KS. Adipose tissue transcriptome changes during obesity development in female dogs. Physiol Genomics 43: 295-307, 2011.

18. Henegar C, Tordjman J, Achard V, Lacasa D, Cremer I, GuerreMillo M, Poitou C, Basdevant A, Stich V, Viguerie N, Langin D, Zucker JD, Clement K. Adipose tissue transcriptomic signature highlights the pathological relevance of extracellular matrix in human obesity. Genome Biol 9: R14, 2008.
19. Hirschey MD, Shimazu T, Goetzman E, Jing E, Schwer B, Lombard DB, Grueter CA, Harris C, Biddinger S, Ilkayeva OR, Stevens RD, Li Y, Saha AK, Ruderman NB, Bain JR, Newgard CB, Farese RV, Alt F, Kahn CR, Verdin E. SIRT3 regulates mitochondrial fatty-acid oxidation by reversible enzyme deacetylation. Nature 464: 121-125, 2010.

20. Huang DW, Sherman BT, Lempicki RA. Systematic and integrative analysis of large gene lists using DAVID bioinformatics resources. Nat Protoc 4: 44-57, 2009.

21. Huang ZH, Gu D, Mazzone T. Role of adipocyte-derived apoE in modulating adipocyte size, lipid metabolism, and gene expression in vivo. Am J Physiol Endocrinol Metab 296: E1110-E1119, 2009.

22. Johnson BJ, Le TTT, Dobbin CA, Banovic T, Howard CB, Flores FDL, Vanags D, Naylor DJ, Hill GR, Suhrbier A. Heat shock protein 10 inhibits lipopolysaccharide-induced inflammatory mediator production. $J$ Biol Chem 280: 4037-4047, 2005.

23. Kim Y, Park T. DNA microarrays to define and search for genes associated with obesity. Biotechnol J 5: 99-112, 2010.

24. Klimcakova E, Roussel B, Kovacova Z, Kovacikova M, SiklovaVitkova M, Combes M, Hejnova J, Decaunes P, Maoret JJ, Vedral T, Viguerie N, Bourlier V, Bouloumie A, Stich V, Langin D. Macrophage gene expression is related to obesity and the metabolic syndrome in human subcutaneous fat as well as in visceral fat. Diabetologia 54: 876-887, 2011.

25. Klimcakova E, Roussel B, Marquez-Quinones A, Kovacova Z, Kovacikova M, Combes M, Siklova-Vitkova M, Hejnova J, Sramkova P, Bouloumie A, Viguerie N, Stich V, Langin D. Worsening of obesity and metabolic status yields similar molecular adaptations in human subcutaneous and visceral adipose tissue: decreased metabolism and increased immune response. J Clin Endocrinol Metab 96: E73-E82, 2011.

26. Laval G, Iannuccelli N, Legault C, Milan D, Groenen MAM, Giuffra E, Andersson L, Nissen PH, Jorgensen CB, Beeckmann P, Geldermann H, Foulley JL, Chevalet C, Ollivier L. Genetic diversity of eleven European pig breeds. Gen Sel Evol 32: 187-203, 2000.

27. Lebret B, Mourot J. Characteristics and quality of pig adipose tissues. Influence of rearing factors. INRA Prod Anim 11: 131-143, 1998.

28. Lee YH, Nair S, Rousseau E, Allison DB, Page GP, Tataranni PA, Bogardus C, Permana PA. Microarray profiling of isolated abdominal subcutaneous adipocytes from obese vs non-obese Pima Indians: increased expression of inflammation-related genes. Diabetologia 48: 1776-1783, 2005.

29. Li XJ, Yang H, Li GX, Zhang GH, Cheng J, Guan H, Yang GS. Transcriptome profile analysis of porcine adipose tissue by high-throughput sequencing. Anim Genet 43: 144-152, 2012.

30. Litten-Brown JC, Corson AM, Clarke L. Porcine models for the metabolic syndrome, digestive and bone disorders: a general overview. Animal 4: 899-920, 2010.

31. Maachi M, Pieroni L, Bruckert E, Jardel C, Fellahi S, Hainque B, Capeau J, Bastard JP. Systemic low-grade inflammation is related to both circulating and adipose tissue TNF alpha, leptin and IL-6 levels in obese women. Int J Obes 28: 993-997, 2004.

32. Matsuzaka T, Shimano H, Yahagi N, Kato T, Atsumi A, Yamamoto T, Inoue N, Ishikawa M, Okada S, Ishigaki N, Iwasaki H, Iwasaki Y, Karasawa T, Kumadaki S, Matsui T, Sekiya M, Ohashi K, Hasty AH, Nakagawa Y, Takahashi A, Suzuki H, Yatoh S, Sone H, Toyoshima H, Osuga JI, Yamada N. Crucial role of a long-chain fatty acid elongase, Elovl6, in obesity-induced insulin resistance. Nat Med 13: 1193-1202, 2007.

33. Merlot E, Vincent A, Thomas F, Meunier-Salaün MC, Damon M, Robert F, Dourmad JY, Lebret B, Prunier A. Health and immune traits of Basque and Large White pigs housed in a conventional or enriched environment. Animal 6: 1290-1299, 2012.

34. Mourot J, Kouba M, Bonneau M. Comparative study of in vitro lipogenesis in various adipose tissues in the growing Meishan pig: Comparison with the Large White pig (Sus domesticus). Comp Biochem Physiol 115: 383-388, 1996.

35. Ortega Martinez de Victoria E, Xu X, Koska J, Francisco AM, Scalise M, Ferrante AW Jr, Krakoff J. Macrophage content in subcutaneous adipose tissue: associations with adiposity, age, inflammatory markers, and whole-body insulin action in healthy Pima Indians. Diabetes 58: 385-393, 2009.

36. Perez-Enciso M, Ferraz ALJ, Ojeda A, Lopez-Bejar M. Impact of breed and sex on porcine endocrine transcriptome: a Bayesian biometrical analysis. BMC Genom 10: 89, 2009. 
37. Poulos SP, Hausman DB, Hausman GJ. The development and endocrine functions of adipose tissue. Mol Cell Endocrinol 323: 20-34, 2010.

38. Reiter SS, Halsey CHC, Stronach BM, Bartosh JL, Owsley WF, Bergen WG. Lipid metabolism related gene-expression profiling in liver, skeletal muscle and adipose tissue in crossbred Duroc and Pietrain pigs. Comp Biochem Physiol D 2: 200-206, 2007.

39. Robert C, Palin MF, Coulombe N, Roberge C, Silversides FG, Benkel BF, McKay RM, Pelletier G. Backfat thickness in pigs is positively associated with leptin mRNA levels. Can J Anim Sci 78: 473-482, 1998.

40. Shi T, Wang F, Stieren E, Tong Q. SIRT3, a mitochondrial sirtuin deacetylase, regulates mitochondrial function and thermogenesis in brown adipocytes. J Biol Chem 280: 13560-13567, 2005.

41. Smyth GK, Speed T. Normalization of cDNA microarray data. Methods 31: 265-273, 2003.

42. Spurlock ME, Gabler NK. The development of porcine models of obesity and the metabolic syndrome. J Nutr 138: 397-402, 2008.

43. Strissel KJ, Stancheva Z, Miyoshi H, Perfield JW, DeFuria J, Jick Z, Greenberg AS, Obin MS. Adipocyte death, adipose tissue remodeling, and obesity complications. Diabetes 56: 2910-2918, 2007.

44. Taleb S, Lacasa D, Bastard JP, Poitou C, Cancello R, Pelloux V, Viguerie N, Benis A, Zucker JD, Bouillot JL, Coussieu C, Basdevant A, Langin D, Clement K. Cathepsin S, a novel biomarker of adiposity: relevance to atherogenesis. FASEB $J$ 19: 1540-1542, 2005.

45. Vandesompele J, De Preter K, Pattyn F, Poppe B, Van Roy N, De Paepe A, Speleman F. Accurate normalization of real-time quantitative RT-PCR data by geometric averaging of multiple internal control genes. Genome Biol 3: 0034.1-0034.11, 2002.
46. Vigilanza P, Aquilano K, Baldelli S, Rotilio G, Ciriolo MR. Modulation of intracellular glutathione affects adipogenesis in 3T3-L1 cells. $J$ Cell Physiol 226: 2016-2024, 2011.

47. Villarroya J, Giralt M, Villarroya F. Mitochondrial DNA: An Up-andcoming actor in white adipose tissue pathophysiology. Obesity 17: 18141820, 2009.

48. Weisberg SP, McCann D, Desai M, Rosenbaum M, Leibel RL, Ferrante AW. Obesity is associated with macrophage accumulation in adipose tissue. J Clin Invest 112: 1796-1808, 2003.

49. Wilson-Fritch L, Nicoloro S, Chouinard M, Lazar MA, Chui PC, Leszyk J, Straubhaar J, Czech MP, Corvera S. Mitochondrial remodeling in adipose tissue associated with obesity and treatment with rosiglitazone. J Clin Invest 114: 1281-1289, 2004.

50. Wolfs MGM, Rensen SS, Dijk E, Verdam FJ, Greve JW, Sanjabi B, Bruinenberg M, Wijmenga C, van Haeften TW, Buurman WA, Franke L, Hofker MH. Co-expressed immune and metabolic genes in visceral and subcutaneous adipose tissue from severely obese individuals are associated with plasma HDL and glucose levels: a microarray study. BMC Med Genomics 3: 34, 2010.

51. Zechner R, Moser R, Newman TC, Fried SK, Breslow JL. Apolipoprotein-E gene-expression in mouse 3T3-L1 adipocytes and human adipose-tissue and its regulation by differentiation and lipid-content. J Biol Chem 266: 10583-10588, 1991.

52. Zhao SH, Recknor J, Lunney JK, Nettleton D, Kuhar D, Orley S, Tuggle CK. Validation of a first-generation long-oligonucleotide microarray for transcriptional profiling in the pig. Genomics 86: 618-625, 2005.

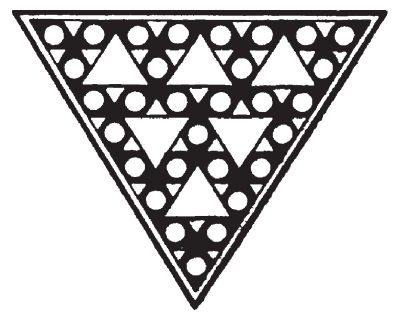

